\title{
FAKTOR - FAKTOR YANG BERHUBUNGAN DENGAN PELAKSANAAN INISIASI MENYUSUI DINI (IMD) DI PUSKESMAS BUTAR KECAMATAN PAGARAN KABUPATEN TAPANULI UTARA TAHUN 2020
}

\author{
Fransiska Debataraja ${ }^{1}$, Nova Sontry Node Siregar ${ }^{2}$, Winta Mariana Batubara ${ }^{3}$ \\ STIKes Kesehatan Baru, Indonesia
}

\begin{tabular}{l} 
Article Info \\
\hline Article history: \\
Received Des 08, 202 \\
Revised Mar 06, 2021 \\
Accepted Mar 13, 202 \\
\hline Keywords: \\
Knowledge \\
Type of Childbirth \\
Husband's Support
\end{tabular}

\section{Article Info}

Received Des 08, 2020

Revised Mar 06, 2021

Accepted Mar 13, 2021

\section{Keywords: \\ Type of Childbirth \\ Husband's Support}

\begin{abstract}
Early Initiation of Breastfeeding (IMD) is an opportunity given to babies immediately after birth by placing the baby on the mother's stomach, then the baby is allowed to find the mother's nipple and breastfeed within the first hour after birth. The UNICEF organization Says that IMD is so important for babies that it calls it the baby's first vaccine. The purpose of this study was to determine the factors related to the implementation of Early Breastfeeding Initiation (IMD) at Butar Public Health Center, Pagaran District, Tapanuli Utara District in 2020. This type of research is a descriptive quantitative study using a cross-sectional design or approach. A total population of 30 people was used with a total sampling technique in which the entire population was sampled. In this research, the population is all post partum mothers in the work area of Butar puskesmas, Butar sub-district, North Tapanuli district. Data were collected by means of a questionnaire, then the data were processed using the chi-square test. The results of the study using the chi-square test with a confidence level of $95 \%(\alpha=0.05)$ showed that there was no relationship between the type of labor and the results of the Fisher's Exact Test with a confidence level of $95 \%$ and $\mathrm{df}=1$ obtained $\mathrm{x} 2$ count $(0.597)<\mathrm{x} 2$ table. (3.841), there is a relationship of knowledge $\mathrm{df}=2$, it is obtained $\mathrm{x} 2$ count $(10.425)>\mathrm{x} 2$ table 5.991, there is a relationship of husband's support. Fisher's Exact Test with a confidence level of $95 \%(\alpha=$ $0.05)$ and $\mathrm{df}=1$ obtained $\mathrm{p}$ value $=0.000(\mathrm{p}<0.05)$, there is a relationship of support for health workers and $\mathrm{df}=2$ obtained $\mathrm{x} 2$ count $(8.450)>\mathrm{n} \times 2$ table (5.991). It is expected that respondents will know the information provided by health workers or from the mass media about the provision and implementation of Early Breastfeeding Initiation (IMD).
\end{abstract}

This is an open access article under the CC BY-SAlicense.

\section{Corresponding Author:}

Fransiska Debataraja, DIII Kebidanan, STIKes Kesehatan Baru JL. Bukit Sipalakki, Kecamatan Doloksanggul, Kabupaten Humbang Hasundutan, Sumatera Utara. Email: fransiska.debataraja@stikeskb.ac.id

\section{INTRODUCTION}

Pembangunan sumber daya manusia tidak lepas dari upaya kesehatan khususnya untuk meningkatkan kesehatan Ibu dan Bayi. Inisiasi Menyusui Dini (IMD) merupakan suatu kesempatan yang diberikan kepada bayi segera setelah lahir dengan cara meletakkan bayi diperut Ibu, kemudian bayi dibiarkan untuk menemukan puting susu ibu dan menyusui hingga puas. Organisasi UNICEF Mengatakan bahwa IMD sangat penting bagi Bayi sehingga menyebutnya sebagai vaksin pertama bayi (UNICEF, 2016). Organisasi 
United Nations Children's Fun (UNICEF) dan Word Healt Organitation (WHO), memperkirakan 78 juta bayi atau 3 dari 5 tidak disusui dalam 1 jam pertama kehidupan dapat meningkatkan resiko terkena penyakit dan kematian. Data dari 76 Negara menunjukkan alasan penundaan Inisiasi Menyusui Dini (IMD) diantaranya yaitu pemberian makanan atau minuman bukan Air Susu Ibu (ASI) dan membuang Kolostrum, tindakan persalinan section caesar, dan adanya kesenjangan dalam kualitas perawatan kepada ibu dan Bayi Baru Lahir. Penelitian sebelumnya mengatakan bahwa Bayi Baru Lahir yang menyusui antara 2 dan 23 jam memiliki resiko kematian 33\% lebih besar dibandingkan dengan Bayi yang menyusu dalam waktu 1 jam setelah lahir (WHO, 2018). Telah merekomendasikan pelaksanaan IMD pada bayi baru lahir yang akan mencegah $22 \%$ kematian bayi di bawah satu bulan di Negara berkembang. Untuk mendukung program pemerintah sebelumnya. IMD berperan dalam pencapian tujuan Sustainable Depelovment Goals (SDGs), yang merupakan acuan dalam kerangka pembangunan dan perundingan Negara yaitu membantu mengurangi angka kemiskinan, kelaparan, serta kematian anak dan Balita. (Kementrian Kesehatan RI 2014), (ASKEB Masa Nifas dan Asuhan Kebidanan III, 2015).

Berdasarkan data (WHO, 2016) dari survey di 24 negara, capaian IMD sebesar 57,6\% secara keseluruhan, dan sebesar 37,2 \% dari jumlah Neonatus dari satu jam pertama setelah lahir dan dari 1-24 jam setelah lahir. Persentasi capaian terendah ditemukan di Peru (17,7\%), dan di Filifina (39.9\%), serta tertinggi ditemukan di Angola (98,4\%), Kuba (89,2\%) dan Sri Lanka sebesar (88,5\%). Mengacu pada target pada tahun 2016 yang sebesar 42\%, maka secara Nasional cakupan pemberian ASI Eksklusif pada Bayi usia kurang dari 6 bulan sebesar 54,0\% telah mencapai target. Menurut Provinsi, cakupan ASI Eksklusif Pada Bayi umur 0-5 bulan berkisar antara 32,2\% (Gorontalo) sampai 79,9\% (NTT). Tercatat hanya 3 Provinsi dari 34 Provinsi yang belum mencapai target.

Berdasarkan Data Kementrian Kesehatan RI tahun 2018, cakupan IMD tahun 2017 untuk Bayi Baru Lahir <1 jam sebesar 51,32\% dan untuk Bayi $\geq 1$ jam sebesar 3,4\% dan ASI Eksklusif sampai 6 bulan sebesar 35,37\% dan ASI Eksklusif 0-5 bulan sebesar 46,74\%. Sumatera Utara berada pada urutan nomor 7 paling rendah cakupan IMDnya. Cakupan IMD pada Bayi Baru Lahir <1 jam Di Sumatera Utara sebesar $38,37 \%$ dan pada BayI Lahir $\geq 1$ jam Di Sumatera Utara 3,47\% ASI Eksklusif sampai 6 bulan. Di Sumatera Utara tahun 2017 sebesar 10,37\% dan ASI Eksklusif 0-5 bulan 25,71\%. (Kementrian Kesehatan RI tahun 2018). Data dari Riskesdes Tahun 2018, proporsi Inisiasi Menyusui Dini (IMD) Pada Anak Umur 0-23 Bulan tidak melaksanakan IMD sebanyak 42,8 \% dan yang melakukan IMD sebanyak 58,2\%, IMD > 1 jam = 11,7\%. Survey awal yang dilakukan penulis pada bulan Mei 2020 Di Puskesmas Butar Kecamatan Pagaran Kabupaten Tapanuli utara diperoleh informasi yang didapat melalui wawancara kepada ibu post partum yang mengatakan bahwa saat proses persalinannya dilakukan, bidan tidak melaksanakan/memberikan Inisiasi Menyusui Dini (IMD). Hal ini juga diakibatkan karena, kurangnya pengetahuan ibu post partum terhadap IMD dan kurangnya keterlibatan Tenaga Kesehatan saat persalinan tidak dilakukan IMD. Oleh karena itu, penulis tertarik untuk melakukan penelitian mengenai "Faktor-faktor yang berhubungan dengan Pelaksanaan Inisiasi Menyusui Dini (IMD) Di Puskesmas Butar Kecamatan Pagaran Kabupaten Tapanuli Utara”.

\section{RESEARCH METHOD}

Jenis penelitian ini merupakan penelitian survey analitik deskriptif dengan menggunakan desain atau pendekatan cross sectional tujuannya untuk mengetahui hubungan pengetahuan ibu post partum terhadap pelaksanaan Inisiasi Menyusui Dini (IMD) Di Puskesmas Butar Kecamatan Pagaran Kabupaten Tapanuli Utara Tahun 2020. Waktu penelitian dilakukan Pada bulan Juni-Agustus 2020. Pada peneltian ini, yang menjadi populasinya adalah seluruh ibu post partum di wilayah kerja puskesmas Butar kecamatan Butar kabupaten Tapanuli Utara tahun 2020 yaitu sebanyak 30 orang. 


\section{RESULTS AND ANALYSIS}

\subsection{Hasil}

\section{Analisa Univariat}

Tabel 1. Distribusi Frekuensi Responden Berdasarkan Jenis Persalinan, Pengetahuan, Dukungan Suami Dan Dukungan Tenaga Kesehatan Di Puskesmas Butar Kecamatan Pagaran Kabupaten Tapanuli Utara Tahun 2020

\begin{tabular}{|c|c|c|c|}
\hline No & Variabel & Jumlah & Persentase $(\%)$ \\
\hline \multicolumn{4}{|c|}{ Pengetahuan } \\
\hline 1 & Baik & 8 & 26,7 \\
\hline 2 & Cukup & 12 & 40,0 \\
\hline 3 & Kurang & 10 & 33,3 \\
\hline \multicolumn{2}{|r|}{ Total } & 30 & 100 \\
\hline \multicolumn{4}{|c|}{ Dukungan suami } \\
\hline 1 & Mendukung & 20 & 66,7 \\
\hline \multirow[t]{2}{*}{2} & Tidak mendukung & 10 & 33,3 \\
\hline & Total & 30 & 100 \\
\hline \multicolumn{4}{|c|}{ Dukungan Tenaga Kesehatan } \\
\hline 1 & Baik & 9 & 30 \\
\hline 2 & Cukup & 15 & 50,0 \\
\hline 3 & Kurang & 6 & 20,0 \\
\hline \multicolumn{2}{|r|}{ Total } & 30 & 100 \\
\hline \multicolumn{4}{|c|}{ Jenis persalinan } \\
\hline 1 & Normal & 23 & 76,7 \\
\hline \multirow[t]{2}{*}{2} & Operasi /Caesar & 7 & 23,3 \\
\hline & Total & 30 & 100 \\
\hline \multicolumn{2}{|c|}{ Pelaksanaan IMD } & \multicolumn{2}{|c|}{+2} \\
\hline & Tidak dilakukan & 10 & 33,3 \\
\hline 2 & Dilakukan & 20 & 66,7 \\
\hline & Total & 30 & 100 \\
\hline
\end{tabular}

Pada tabel 1 Berdasarkan pengetahuan ibu, yang berpengetahuan kategori baik sebanyak 8 responden $(26,7 \%)$ berpengetahuan kategori cukup sebanyak 12 responden (40,0\%), dan pengetahuan ibu pada kategori kurang sebanyak 10 responden $(33,3 \%)$. Berdasarkan dukungan suami terhadap pelaksanaan IMD yaitu dukungan suami baik sebanyak 9 responden (30\%), dukungan suami kategori cukup sebanyak 15 responden $(50 \%)$ dan dukungan suami kategori kurang sebanyak 6 responden $(20 \%)$.

Berdasarkan dukungan tenaga kesehatan dalam pelaksanaan IMD yaitu dukungan tenaga kesehatan pada kategori baik sebanyak 9 responden (30\%), kategori cukup sebanyak 15 responden (50\%) dan dukungan tenaga kesehatan yang kurang sebanyak 6 responden (20\%). Dari 30 responden berdasarkan jenis persalinan yang melakukan persalinan secara normal sebanyak 23 responden $(76,7 \%)$ dan jenis persalinan secara operasi/Ceaser sebanyak 7 responden (23,3\%). Berdasarkan pelaksanaan IMD dari 30 responden, yang tidak melakukan pelaksanaan IMD sebanyak 10 responden $(33,3 \%)$, yang melakukan pelaksanaan IMD sebanyak 20 responden $(66,7 \%)$.

\section{Analisa Bivariat}

Tabel 2. Distribusi Frekuensi Hubungan Pengetahuan Terhadap Pelaksanaan Inisiasi Menyusui Dini (IMD) Berdasarkan Pengetahuan Di Puskesmas Butar Kecamatan Pagaran Kabupaten Tapanuli Utara Tahun 2020

Pelaksanaan IMD

\begin{tabular}{|c|c|c|c|c|c|c|c|c|c|}
\hline \multirow[t]{2}{*}{ No } & \multirow[t]{2}{*}{ Pengetahuan } & \multicolumn{2}{|c|}{ Tidak Dilakukan } & \multicolumn{2}{|c|}{ Dilakukan } & \multicolumn{2}{|c|}{ Total } & \multirow[t]{2}{*}{ df } & \multirow{2}{*}{ P Value } \\
\hline & & n & $\%$ & $\mathbf{n}$ & $\%$ & $\mathbf{N}$ & $\%$ & & \\
\hline 1 & Baik & 0 & 0 & 8 & 100 & 8 & 100 & \multirow{3}{*}{2} & \multirow{3}{*}{0,005} \\
\hline 2 & Cukup & 3 & 25,0 & 9 & 75,0 & 12 & 100 & & \\
\hline 3 & Kurang & 7 & 70,0 & 3 & 30,0 & 10 & 100 & & \\
\hline
\end{tabular}

Berdasarkan tabel 2 dapat dilihat bahwa dari 30 responden, diketahui bahwa 8 responden berpengetahuan baik yang tidak melakukan pelaksanaan IMD tidak ada dan yang melakukan IMD sebanyak 8 responden $(100 \%)$. Dari 12 responden berpengetahuan cukup yang melakukan pelaksanaan IMD sebanyak 3 responden $(25 \%)$ dan yang tidak melakukan IMD sebanyak 9 responden (75\%). Dari 10 responden berpengetahuan kurang yang tidak melakukan pelaksanaan IMD sebanyak 7 responden (70\%) dan yang melakukan pelaksanaan IMD sebanyak 3 responden (30\%). 
Dengan menggunakan uji chi-square dengan tingkat kepercayaan $95 \%(\alpha=0,05)$ dan df $=2$ diperoleh $\mathrm{p}$ value $(0,005)<\alpha(0,05)$, maka Ha diterima, Ho ditolak berarti ada hubungan pengetahuan terhadap hubungan pengetahuan terhadap pelaksanaan Inisiasi Menyusui Dini (IMD) di Puskesmas Butar Kecamatan Pagaran Kabupaten Tapanuli Utara Tahun 2020.

Tabel 3. Distribusi Frekuensi Faktor- faktor yang berhubungan Terhadap Pelaksanaan Inisiasi Menyusui Dini (IMD) Berdasarkan Dukungan Suami Di Puskesmas Butar Kecamatan Pagaran Kabupaten Tapanuli Utara Tahun 2020

\begin{tabular}{|c|c|c|c|c|c|c|c|c|c|}
\hline \multirow{3}{*}{ No } & \multirow{3}{*}{ Dukungan Suami } & \multicolumn{6}{|c|}{ Pelaksanaan IMD } & \multirow{3}{*}{ df } & \multirow{3}{*}{ P Value } \\
\hline & & \multicolumn{2}{|c|}{ Tidak Dilakukan } & \multicolumn{2}{|c|}{ Dilakukan } & \multicolumn{2}{|c|}{ Total } & & \\
\hline & & n & $\%$ & $\mathbf{n}$ & $\%$ & $\mathbf{N}$ & $\%$ & & \\
\hline 1 & Tidak mendukung & 8 & 80,0 & 2 & 20,0 & 10 & 100,0 & 1 & O $00 \Omega$ \\
\hline 2 & Mendukung & 2 & 10,0 & 18 & 90,0 & 20 & 100,0 & 1 & \\
\hline
\end{tabular}

Berdasarkan tabel 3 diatas diketahui bahwa dari 30 responden, yang diketahui bahwa dari 10 responden yang dukungan suami dalam pelaksanaan IMD dengan tidak mendukung sebanyak 8 responden (80\%), yang dukungan suami dan pelaksanaan IMD dengan dilakukan ada 2 responden (20\%). Dari 20 responden yang dukungan suami dalam pelaksanaan IMD dengan tidak mendukung ada 2 orang (10\%), yang dukungan suami terhadap pelaksanaan IMD yang mendukung sebanyak 18 responden $(90,0 \%)$.

Dengan menggunakan uji fisher's Exact Test dengan tingkat kepercayaan $95 \%(\alpha=0,05)$ dan $\mathrm{df}=1$ diperoleh $\mathrm{p}$ value $=0,000(\mathrm{p}<0,05)$, maka Ha diterima, Ho ditolak berarti ada hubungan dukungan suami terhadap hubungan pengetahuan ibu post partum terhadap pelaksanaan Inisiasi Menyusui Dini (IMD) di Puskesmas Butar Kecamatan Pagaran Kabupaten Tapanuli Utara Tahun 2020.

Tabel 4. Distribusi Frekuensi Faktor - Faktor Yang Berhubungan Terhadap Pelaksanaan Inisiasi Menyusui Dini (IMD) Berdasarkan Dukungan Tenaga Kesehatan Di Puskesmas Butar Kecamatan Pagaran Kabupaten Tapanuli Utara Tahun 2020

\begin{tabular}{|c|c|c|c|c|c|c|c|c|c|}
\hline \multirow{3}{*}{ No } & \multirow{3}{*}{$\begin{array}{l}\text { Dukungan } \\
\text { Tenaga } \\
\text { Kesehatan }\end{array}$} & \multicolumn{6}{|c|}{ Pelaksanaan IMD } & \multirow{3}{*}{ df } & \multirow{3}{*}{ P Value } \\
\hline & & \multicolumn{2}{|c|}{ Tidak Dilakukan } & \multicolumn{2}{|c|}{ Dilakukan } & \multicolumn{2}{|c|}{ Total } & & \\
\hline & & n & $\%$ & n & $\%$ & $\mathbf{N}$ & $\%$ & & \\
\hline 1 & Baik & 2 & 22,2 & 7 & 77,8 & 9 & 100 & & \\
\hline 2 & Cukup & 3 & 20,0 & 12 & 80,0 & 15 & 100 & 2 & 0,015 \\
\hline 3 & Kurang & 5 & 83,3 & 1 & 16,7 & 6 & 100 & & \\
\hline
\end{tabular}

Berdasarkan tabel 4 dapat dilihat bahwa dari 30 responden, dari 9 responden dukungan tenaga kesehatan kategori baik yang tidak melakukan pelaksanaan IMD sebanyak 2 responden $(22,2 \%)$ dan yang melakukan sebanyak 7 responden $(77,8 \%)$. Dari 15 responden dukungan tenaga kesejatan kategori cukup yang tidak melakukan pelaksanaan IMD sebanyak 3 responden $(20 \%)$ dan yang melakukan pelaksanaan IMD sebanyak 12 responden $(80 \%)$. Dari 6 responden dukungan kesehatan kategori kurang sebanyak yang tidak melakukan pelaksanaan IMD sebanyak 5 responden $(83,3 \%)$ dan yang melakukan pelaksanaan IMD sebanyak 1 responden $(16,7 \%)$.

Dengan menggunakan uji chi-square dengan tingkat kepercayaan 95\% $(\alpha=0,05)$ dan df $=2$ diperoleh $\mathrm{p}$ Value $(0,015)<\alpha(0,05)$, maka, Ha diterima, Ho ditolak berarti ada hubungan dukungan tenaga kesehatan terhadap hubungan pengetahuan ibu post partum terhadap pelaksanaan Inisiasi Menyusui Dini (IMD) Di Puskesmas Butar Kecamatan Pagaran Kabupaten Tapanuli Utara Tahun 2020.

Tabel 5. Distribusi Frekuensi Faktor - Faktor Yang Berhubungan Terhadap Pelaksanaan Inisiasi Menyusui

Dini (IMD) Berdasarkan Jenis Persalinan Di Puskesmas Butar Kecamatan Pagaran Kabupaten Tapanuli Utara Tahun 2020

\begin{tabular}{|c|c|c|c|c|c|c|c|c|c|}
\hline \multirow{3}{*}{ No } & \multirow{3}{*}{ Jenis Persalinan } & \multicolumn{6}{|c|}{ Pelaksanaan IMD } & \multirow{3}{*}{ df } & \multirow{3}{*}{ P Value } \\
\hline & & \multicolumn{2}{|c|}{ Tidak Dilakukan } & \multicolumn{2}{|c|}{ Dilakukan } & \multicolumn{2}{|c|}{ Total } & & \\
\hline & & n & $\%$ & $\mathbf{n}$ & $\%$ & $\mathbf{N}$ & $\%$ & & \\
\hline 1 & Normal & 8 & 34,8 & 15 & 65,2 & 23 & 100,0 & \multirow{2}{*}{1} & \multirow{2}{*}{0.000} \\
\hline 2 & Operasi /Caesar & 2 & 28,6 & 5 & 71,4 & 7 & 100,0 & & \\
\hline
\end{tabular}

Berdasarkan tabel 5 diatas diketahui bahwa dari 23 responden dengan jenis persalinan normal yang tidak melakukan pelaksanaan IMD sebanyak 8 responden $(34,8 \%)$ dan yang melakukan pelaksnaan IMD sebanyak 15 responden $(65,2 \%)$. Dari 7 responden jenis persalinannya secara operasi/Ceaser yang tidak melakukan pelaksanaan IMD sebanyak 2 responden $(28,6 \%)$ dan yang melakukan pelaksanaan IMD sebanyak 20 responden (66,7\%). Dengan menggunakan uji Fisher's Exact Test dengan tingkat kepercayaan $95 \%$ dan $\mathrm{df}=1$ diperoleh $\mathrm{P}$ value $(1,000)<\alpha(0,05)$, maka Ha ditolak, $\mathrm{H}_{\mathrm{o}}$ diterima berarti tidak ada hubungan antara jenis persalianan dengan hubungan pengetahuan ibu post partum terhadap pelaksanaan 
Inisiasi Menyusui Dini (IMD) di Puskesmas Butar Kecamatan Pagaran Kabupaten Tapanuli Utara Tahun 2020 .

\subsection{Pembahasan}

Faktor- Faktor Yang Berhubungan Terhadap Pelaksanaan Inisiasi Menyusui Dini (IMD) Berdasarkan Pengetahuan

Dengan menggunakan uji chi-square dengan tingkat kepercayaan 95\% $(\alpha=0,05)$ dan df $=2$ diperoleh $\mathrm{P}$ value $(0,005)<\alpha(0,05)$, maka Ha diterima, Ho ditolak berarti ada hubungan pengetahuan terhadap hubungan pengetahuan dan terhadap pelaksanaan Inisiasi Menyusui Dini (IMD) Di Puskesmas Butar Kecamatan Pagaran Kabupaten Tapanuli Utara Tahun 2020.

Hasil penelitian bahwa dari 8 responden yang berpengetahuan baik semua melakukan pelaksanaan IMD. Dan yang tidak melakukan pelaksanaan IMD tidak ada. Hasil penelitian ini sesuai dengan hasil penelitian yang dilakukan oleh (Kusmita, 2015) mengenai "Hubungan Tingkat Pengetahuan Ibu Dengan IMD Dengan IMD Di BPM Endang Pleret Bantul Yogyakarta" menunjukkan bahwa hasil uji chi-squared bahwa ada pengaruh hubungan pengetahuan dengan IMD dengan hasil $p$ value $(0,000)$.

Hasil penelitian ini juga diperkuat dengan hasil penelitian yang dilakukan oleh (Erli Zaenal, et al., 2014) dengan judul "Hubungan Pengetahuan dan Sikap Ibu dengan Pelaksanaan Inisiasi Menyusui Dini (IMD) di Rumah Sakit Muhammadyah Gamping Sleman Yogyakarta" menyatakan bahwa ibu yang memiliki pengetahuan dan sikap terhadap pelaksanaan IMD. Didapati hasil bahwa ada hubungan yang bermakna secara signifikan dengan nilai p value 0.016 dengan nilai PR 2,136 (CI 95\% 1,169-4,587). Hubungan sikap ibu menurut (Notoadmodjo, 2010), pengetahuan adalah hasil tahu yang dapat diperoleh dari panca indra seperti mata, telinga, mulut, lidah, kulit dan lainnya.pengetahuan yang baik akan menghasilkan perilaku yang baik, begitu pula sebaliknya perilaku yang tidak baik akan mempengaruhi pelaku seseorang menjadi tidak baik. Sehingga pegetahuan dapat mempengaruhi perilaku seseorang.

\section{Faktor-Faktor Yang Berhubungan Pelaksanaan Inisiasi Menyusui Dini (IMD) Berdasarkan Dukungan Suami}

Dengan menggunakan uji fish'r exact Test dengan tingkat kepercayaan $95 \%(\alpha=0,05)$ dan df $=1$ diperoleh $\mathrm{p}$ value $=0,000(\mathrm{p}<0,05)$, maka Ha diterima, Ho ditolak berarti ada hubungan dukungan suami terhadap hubungan pengetahuan ibu post partum terhadap pelaksanaan Inisiasi Menyusui Dini (IMD) Di Puskesmas Butar Kecamatan Pagaran Kabupaten Tapanuli Utara Tahun 2020.

Hasil penelitian pada tabel 3 dari penelitian ini, dari 20 responden mendukung sebanyak 18 responden yang menyatakan bahwa bayi mereka melakukan Inisiasi Menyusui Dini (IMD). Hal ini memberikan gambaran bahwa pelaksanaan IMD sangat memerlukan dukungan dari suami dimana dukungan tersebut yang paling dibutuhkan oleh ibu menyusui. Hal ini sesuai dengan pendapat (Roesli, 2008) bahwa kondisi emosi yang stabil menentukan tingkat produksi ASI yang dihasilkan ibu. Kestabilan emosi tersebut, bisa diraih bila sang suami turut mendukung.

Dukungan emosi termasuk memberikan pengertian,membesarkan hati dan menyayangi. Dukungan pertolongan termasuk member pertolongan fisik untuk dapat menyusui bayinya. Hal ini juga sasuai dengan apa yang dikemukakan Roesli bahwa dalam tatalaksana Inisiasi Menyusui Dini secara umum, dianjurkan untuk suami mendampingi ibu saat persalinan.

Penelitian ini sejalan dengan penelitian oleh (Suryani dkk, 2011) diperoleh sejumlah responden dengan persentasi mendukung sebesar $60,0 \%$ dan tidak mendukung sebanyak $40,0 \%$. berdasarkan hasil uji dalam penelitian ini dapat disimpulkan bahwa ada hubungan yang signifikan antara dukungan suami dan pelaksanaan Inisiasi Menyusi Dini Dini (IMD) dengan nilai Pvalue 0,004 $<\alpha=0,05$.

\section{Faktor-Faktor Yang Berhubungan Terhadap Pelaksanaan Inisiasi Menyusui Dini (IMD) Berdasarkan Dukungan Tenaga Kesehatan}

Dengan menggunakan uji chi-square dengan tingkat kepercayaan 95\% $(\alpha=0,05)$ dan df $=2$ diperoleh $\mathrm{P}$ value $(0,015)<\alpha(0,05)$, maka Ha diterima, Ho ditolak berarti ada hubungan dukungan tenaga kesehatan terhadap hubungan pengetahuan ibu post partum terhadap pelaksanaan Inisiasi Menyusui Dini (IMD) Di Puskesmas Butar Kecamatan Pagaran Kabupaten Tapanuli Utara Tahun 2020.

Hasil penelitian pada tabel 4 dari 15 responden yang dukungan tenaga kesehatan cukup dengan dilakukan pelaksanaan IMD ada 12 orang Menurut penelitian (Gagat, 2014) mengungkapkan bahwa dukungan tenaga kesehatan yang baik terhadap pemberian IMD pun dapat mendorong peningkatan pemberian IMD oleh ibu. Peran tenaga kesehatan sebagai penolong persalinan sangat penting dalam menyukseskan pemberian IMD kepada bayi oleh ibu. Keterampilan teknis yang baik kemudian akan mendorong sikap yang positif diantara bidan untuk melakukan Inisiasi Menyusui Dini. Hal ini selaras dengan 
penelitian yang dilakukan oleh (Yulianty, 2010) yang menyatakan bahwa ada hubungan dukungan petugas kesehatan Pada ibu pasca bersalin normal dengan nilai $\mathrm{P}$ value $0,000<\alpha=0,05$.

\section{Faktor-Faktor Yang Berhubungan Terhadap Pelaksanaan Inisiasi Menyusui Dini (IMD) Berdasarkan} Jenis Persalinan

Dengan menggunakanuji Fisher's Exact Test dengan tingkat kepercayaan 95\% dan df=1 diperoleh $\mathrm{P}$ value $(1,000)>\alpha(0,05)$, maka Ha ditolak, Ho diterima berarti tidak ada hubungan antara jenis persalianan dengan hubungan pengetahuan ibu post partum terhadap pelaksanaan Inisiasi Menyusui Dini (IMD) Di Puskesmas Butar Kecamatan Pagaran Kabupaten Tapanuli Utara Tahun 2020.

Hal ini didapatkan dari 30 responden yang jenis persalinannya normal sebanyak sebanyak 23 responden, yang melaksanakan IMD sebanyak 15 respoden $(65,2 \%)$ dan yang tidak 8 responden $(34,8 \%)$ dan responden yang jenis persalinannya ceaser/operasi sebanyak 7 responden yang melakukan melaksanakan IMD sebanyak 5 responden $(71,4 \%)$ dan yang tidak melakukan IMD sebanyak 2 responden (28,6\%). Ini diartikan bahwa tidak ada hubungannya jenis persalinan baik secara normal maupun operasi dengan pelaksanaan IMD.

\section{CONCLUSION}

Berdasarkan hasil penelitian dari 30 responden dapat diambil kesimpulan

1. Ada hubungan pengetahuan terhadap pelaksanaan Inisiasi Menyusui Dini (IMD) Di Puskesmas Butar Kecamatan Pagaran Kabupaten Tapanuli Utara Tahun 2020.

2. Ada hubungan dukungan suami terhadap pelaksanaan Inisiasi Menyusui Dini (IMD) Di Puskesmas Butar Kecamatan Pagaran Kabupaten Tapanuli Utara Tahun 2020.

3. Ada hubungan tenaga kesehatan pengetahuan pelaksanaan Inisiasi Menyusui Dini (IMD) Di Puskesmas Butar Kecamatan Pagaran Kabupaten Tapanuli Utara Tahun 2020.

\section{REFERENCES}

1. Dinartiana, A, Sumini, N.L. Agustus 2011. Hubunga pelaksanaan IMD Dengan Keberhasilan ASI EKSKLUSIF pada ibu yang mempunyai bayi 7- 12 bulan di kota Semarang.

2. Gupta. 2007. Tujuan Inisiasi Menyusui Dini. Jakarta: EGC.

3. Kemenkes RI. 2014. Peraturan Mentri Kesehatan RI No, 97 Tahun 2014 Tentang Pelayananan Kesehatan, Masa Sebelum Hamill, Persalinan, Masa Sesudah Melahirkan, Penyelenggaraan Pelayanann Kontrasepsi. Jakarta: Kemenkes RI.

4. Maeyunani, A. 2015. Inisiasi Menyusui Dini, ASI Eksklusif dan Manajemen Laktasi. Jakarta: Trans Info Media.

5. Notoatmodjo, S. 2007. Promosi Kesehatan dan Ilmu Perilaku. Jakarta: Rineka Cipta.

6. Purwanti. 2004. Konsep Penerapan ASI Eksklusif. Bandung: Cendekia.

7. Rudiyanti, Novita. April 2013. Faktor - faktor yang berhubungan Dengan Pelaksanaan Inisiasi Menyusui Dini.

8. Roesli, Utani. 2005. Mengenai ASI EKSKLUSIF. Jakarta: Trubus Agriwidiya.

9. Setiarini. T. 2012. Faktor-Faktor Yang Berhubungan Dengan Kinerja Bidan Dalam Pelaksanaan IMD. Tesis. Jakarta: Universitas Indonesia.

10.Saleha, S. 2013. Asuhan Kebidanan pada Masa Nifas. Jakarta: Salemba Medika.

\section{BIOGRAPHIES OF AUTHORS}

\begin{tabular}{|l|l|}
\hline & $\begin{array}{l}\text { Fransiska Debataraja, Gelar D-III diperoleh dari Akademi Kebidanan Kesehatan } \\
\text { Baru, Jurusan Kebidanan Tahun 2014. Gelar D-IV diperoleh dari STIKes Helvetia } \\
\text { Medan, Jurusan Kebidanan Tahun 2015. Magister Kesehatan Masyarakat diperoleh } \\
\text { dari Institut Kesehatan Helvetia Medan, Peminatan Kesehatan Reproduksi pada tahun } \\
\text { 2017. Saat ini aktif sebagai dosen tetap di STIKes Kesehatan Baru Prodi D-III } \\
\text { Kebidanan dan menjabat sebagai Ketua Lembaga Penjaminan Mutu. }\end{array}$ \\
\hline
\end{tabular}




\begin{tabular}{|l|l|} 
Nova Sontry Node Siregar, Gelar D-III diperoleh dari Akademi Kebidanan Kesehatan \\
Baru, Jurusan Kebidanan Tahun 2009. Sarjana Kesehatan Masyarakat diperoleh dari \\
Universitas Prima Indonesia, Jurusan Ilmu Kesehatan Masyarakat Tahun 2011. \\
Magister Kesehatan Masyarakat diperoleh dari Universitas Sumatera Utara (USU), \\
Peminatan Kesehatan Reproduksi pada tahun 2013. Saat ini aktif sebagai dosen tetap di \\
STIKes Kesehatan Baru Prodi D-III Kebidanan dan menjabat sebagai Ketua STIKes \\
Kesehatan Baru.
\end{tabular}

